\title{
Experimental Research on Upslope Fire and Jump Fire
}

\author{
XIAODONG XIE ${ }^{1}$, NAIAN LIU ${ }^{1}$, DOMINGOS X. VIEGAS ${ }^{2}$, JORGE R. RAPOSO ${ }^{2}$ \\ ${ }^{1}$ State Key Laboratory of Fire Science, University of Science and Technology of China, Hefei, \\ 230026, China \\ ${ }^{2}$ Department of Mechanical Engineering, University of Coimbra, 3030-788, Coimbra, Portugal
}

\begin{abstract}
This paper presents an elementary analysis on the difference and similarity between upslope fire and jump fire, by a series of experiments performed in laboratory. The rate of spread (ROS), fire line angle (separation angle of the two fire lines), angular velocity of fire line, flame residence time and nondimensional radiant heat transfer for the two kinds of phenomena are investigated. For upslope fire, it is found that ROS remains almost steady for line ignition, while it increases with time for point ignition. For upslope fires with line ignition, the fire line angle decreases with time from the initial $180^{\circ}$ to a steady small value, while for point ignition, the initially generated fire line angle remains steady. The angular velocity of fire line does not depend on slope angle in an upslope fire with line ignition. For jump fire, the ROS first increases sharply and then decreases gradually, and it depends on slope angle more significantly than the initial fire line angle. The fire line angle increases with time, and the angular velocity of fire line varies with slope angle. For upslope fires with line ignition, the flame residence time increases with slope angle, while it remains almost constant for upslope tests with point ignition. For jump fire, under one specific initial fire line angle, the overall mean residence time increases with increasing slope angle. Nondimensional heat radiation for fuel preheating is calculated which effectively explains the ROS development in upslope fire with line ignition and jump fire.
\end{abstract}

KEYWORDS: upslope fire, jump fire, fire line angle, ROS, residence time, heat radiation

\section{NOMENCLATURE LISTING}

$\begin{array}{llll}\alpha & \text { slope angle }\left(^{\circ}\right) & R & \text { rate of fire spread }(\mathrm{cm} / \mathrm{s}) \\ \theta & \text { fire line angle }\left(^{\circ}\right) & R_{0} & \text { rate of spread with zero-slope and no-wind }(\mathrm{cm} / \mathrm{s}) \\ \theta_{0} & \text { initial fire line angel }\left(^{\circ}\right) & R^{\prime} & \text { non-dimensional rate of spread } \\ \beta & \text { inclination angle of fire line }\left(^{\circ}\right) & t & \text { time }(\mathrm{s}) \\ \gamma & \text { flame tilting angle }\left({ }^{\circ}\right) & w & \text { angular velocity of fire line }(\% / \mathrm{s}) \\ Q & \text { heat release rate }(\mathrm{kW}) & T & \text { flame temperature }(\mathrm{K}) \\ q & \text { heat flux }\left(\mathrm{kW} / \mathrm{m}^{2}\right) & T_{w} & \text { ambient temperature }(\mathrm{K}) \\ q^{*} & \text { non-dimensional heat flux } & A_{1} & \text { flame area }\left(\mathrm{m}^{2}\right) \\ \varepsilon & \text { Emissivity } & A_{2} & \text { area of fuel bed element }\left(\mathrm{m}^{2}\right) \\ \sigma & \text { Stefan-Boltzmann constant } & F_{12} & \text { view factor from flame surface to fuel bed }\end{array}$

\section{INTRODUCTION}

The evolution of a wildland fire depends on a wide range of factors including the interactions between wind and slope, fuel structure and properties, fuel pyrolysis and combustion, and the physical and chemical properties of flames and heat transportation [1]. Slope effect has been considered in many wildfire behavior models [2-7] and fire behavior prediction tools for determining the rate of spread (ROS). In 1970s, Rothermel [8] assumed a simple analogy between wind and slope in his model, in which he used an empirical formulation obtained by experiments to predict the effect of slope on ROS. However, many later studies revealed that there exist very complex physical mechanisms by which slope may exert significant effects on the flame shape, heat transfer and fire intensity. For example, in a surface fire slope may make the flame tilt forward over the unburnt fuels, extending the preheating range and thus leading to more intense burning behavior and higher ROS. Slope may also affect the flame residence time and fire line contours [10]. Silvani [11] indicated that when the slope angle is increased, the fire topology could undergo a change from a U-shape to a V-shape. It was observed that an upslope fire will first involve an initial line fire front, and will then develop to a fire front of $\mathrm{V}$-shape, with significant increases of burning intensity and ROS. Basically, a V-shape fire line is generated due to uneven heat flux distribution in unburnt fuel ahead of flame font in upslope fire. When the slope angle is increased, both radiant and convective heat 
transfers become more significant along the centerline of fuel bed, which may cause the fire front of Vshape.

Besides upslope fires, the $\mathrm{V}$-shape fire front is also concerned with another fire phenomenon called "jump fire", which is a new concept proposed by Viegas [12]. A jump fire denotes the phenomenon that two fire fronts (generally with a small separation angle) spread and meet each other, making up of a V-shape fire topology, and then merge to produce very high rates of spread because of high concentration of energy. Viegas [12] pointed out that the importance of jump fire lies in two aspects. Firstly, in some fire accidents two spreading fire lines were observed to intersect and merge, which led to a jump fire. Second, jump fire is a problem concerned with the safety of prescribed burn.

The similarity between upslope fire and jump fire lies in that they both involve high rates of spread of the intersection point between the two fire fronts in V-shape, which suggests that the heat transfer processes especially heat radiation may be significantly enhanced due to the special geometric configurations involved in the two phenomena. In practice, an upslope fire may evolve to an eruptive fire which usually occurs in canyons or steep slopes and is characterized by a quick acceleration of the spread rate of the head fire [13-15]. Although upslope fire and jump fire share the common features of V-shape fire fronts and high rates of spread of the intersection point between the fire fronts, they may differ from each other in physical mechanisms and behaviors. Basically, as indicated by Viegas [12], the generation of a jump fire is related to the interactions between the two fire lines that intersect with a relatively small angle between them, which lead to the merging of the fire lines and sharp increase of the displacement velocity of the intersection point.

This study presents the results of a series of experiments which were designed to examine the relevance between upslope fire and jump fire, and to explore their differences in fire behaviors. The rate of spread, fire line angle (separation angle of the two fire lines), angular velocity of fire line, flame residence time and non-dimensional radiant heat transfer were measured and discussed. Especially the non-dimensional heat radiation flux is calculated to explain the physical dependence of the two phenomena on the fire line angle.

\section{EXPERIMENTAL}

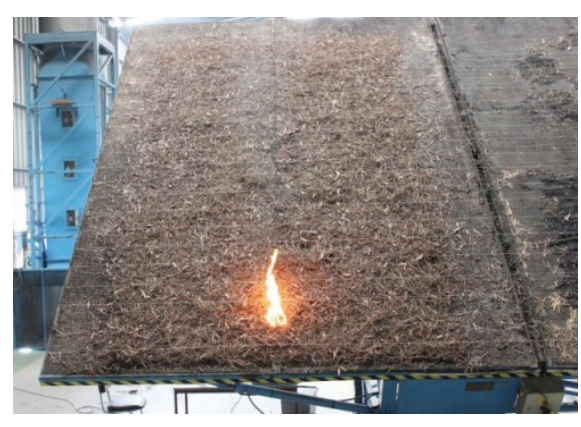

(a)

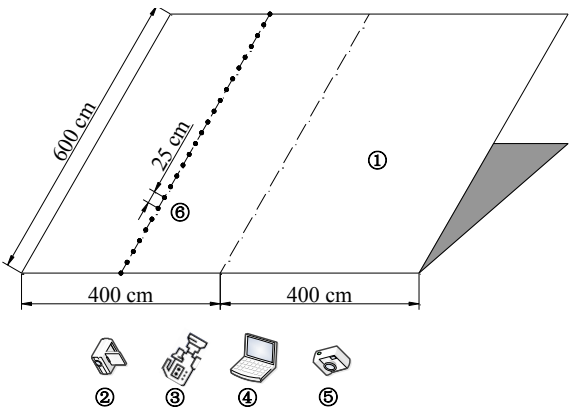

(b)

(1) Combustible table

(2) DV camera

(3) Infrared camera

(4) Data acquisition system

(5) Camera

(6) Thermocouples

Fig. 1. Experimental table, (a) fuel bed; (b) experiment schematic diagram

All the experiments were performed at the Forest Fire Research Laboratory of University of Coimbra, Portugal. The experimental bench had a size of $6.0 \times 8.0 \mathrm{~m}^{2}$, for which the slope angle $\alpha$ could be varied within $0 \sim 40^{\circ}$ (Fig. 1). In all tests the fuel bed consisted of fuels of dead pine needle and shrub, and the fuels were laid as evenly as possible to keep a fuel load of $0.6 \mathrm{~kg} \mathrm{~m}^{-2}$ of dry basis. For upslope fire two kinds of experiments were performed: (1) Line ignition. The fuels were ignited by using a cotton string dipped with mixture of gasoline and diesel, with the same width as that of the fuel bed of $1.0 \mathrm{~m}$ (width) $\times 5.5 \mathrm{~m}$ (length), to produce a line ignition. By this means the fuels along the bottom end of the fuel area were ignited simultaneously, and then an upslope fire began to spread. Different slope angles were used for tests. (2) Point ignition. The fuels were ignited by a small cotton ball soaked in gasoline and diesel $0.5 \mathrm{~m}$ away from the bottom end along the centerline of the fuel bed of $3 \mathrm{~m}$ (width) $\times 5.25 \mathrm{~m}$ (length). For comparison, the rate of spread $R_{0}$ under zero-slope and no-wind condition was tested for both line ignition and point ignition. For jump fire, pine needles were used in all tests, and in each test two line ignitions were used to 
generate two initial fire lines which burn simultaneously after ignition. The fuel area subject to fire spread depended on the initial fire line angle. Both the slope angle and the initial fire line angle were varied for tests. The type $\mathrm{K}$ thermocouples used in experiments have a wire diameter of $0.2 \mathrm{~mm}$ and response time less than $0.1 \mathrm{~s}$. The thermocouples were placed in the centerline of the fuel bed with a constant spacing of $25 \mathrm{~cm}$ (see Fig. 1(b)), and were installed $3 \mathrm{~cm}$ above the top surface of the fuel bed. The temperature data was collected at a sampling frequency of $10 \mathrm{~Hz}$, and it is mainly used to identify the intersection point of the fire lines and to determine the flame residence time. A DV camera and an infrared camera were used to capture the fire spread process. The fire line angle and flame shape were extracted from video images. A compensation algorithm was used to adjust the view angle difference of any camera.

\section{RESULTS AND DISCUSSION}

\section{Rate of Fire Spread (ROS)}

The rate of fire spread (ROS) is defined as the displacement rate of the intersection point of the fire lines, and is obtained from the derivative of the curve "intersection point position vs. time". Figure 2 shows the measured temperature for the upslope fire test with line ignition under the slope angle of $30^{\circ}$, with pine needles as the fuels. The intersection point position is determined by identifying the time moments when the temperatures measured by the thermocouples reached $350{ }^{\circ} \mathrm{C}$ (estimation as the ignition temperature), for which the radiant errors can be neglected. The flame front shapes in the tests of upslope fire (line ignition and point ignition) and jump fire are shown in Fig. 3. It can be seen from Fig. 4 that, for line ignition with pine needle and shrub as the fuels, the fire spread rates are highly steady in global sense for all the slopes. The line plots are the linear regression lines for the experimental data, nearly all of which involve high correlation coefficients. Comparatively, the data for point ignition shows unsteady rate of spread (Fig. 5), and thus polynomial correlations are used for data fitting. Obviously, the ROS increases with time, which may be caused by the gradually increasing lengths of the fire lines (see Fig. 5).

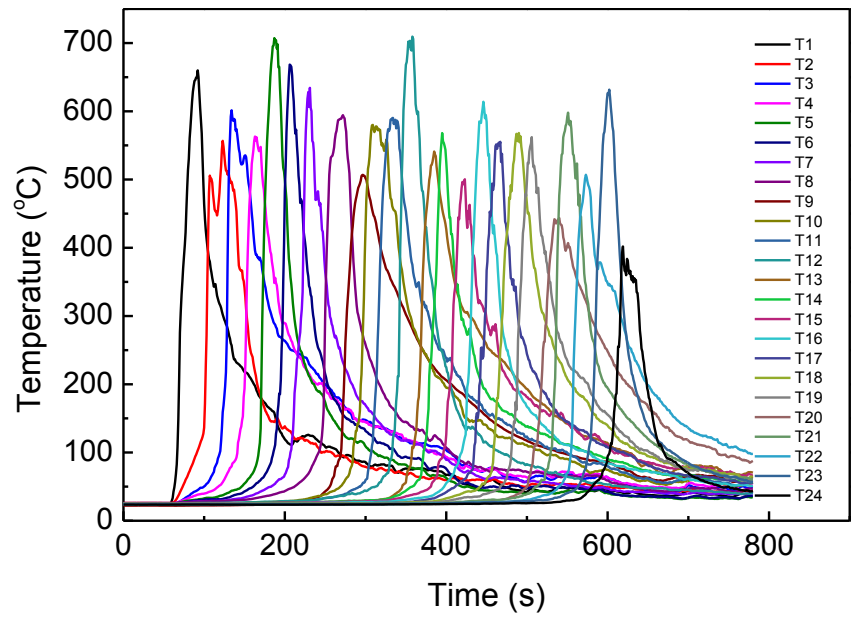

Fig. 2. Temperature data for the upslope fire test with line ignition (pine needles, $\alpha=30^{\circ}$ )

Figure 6(a) shows the data of intersection point position versus time for jump fire tests under different slope angles from three experiments, with a constant initial fire line angle of $\theta_{0}=30^{\circ}$. As seen, the ROS decays with time for all the curves, which obviously differs from the variation mode of ROS in Fig. 5. The moment when the ROS underwent a sharp increase within a short time period could not be captured due to the limitation of experimental means. For a constant slope angle $\alpha=30^{\circ}$, it can be seen from Fig. 6-b that the intersection point position as a function of time shows very similar tendency for different initial fire line angles $\theta_{0}$. Figures 6(a) and (b) indicate that the ROS depends on the slope angle $\alpha$ more significantly than the initial fire line angle $\theta_{0}$. 


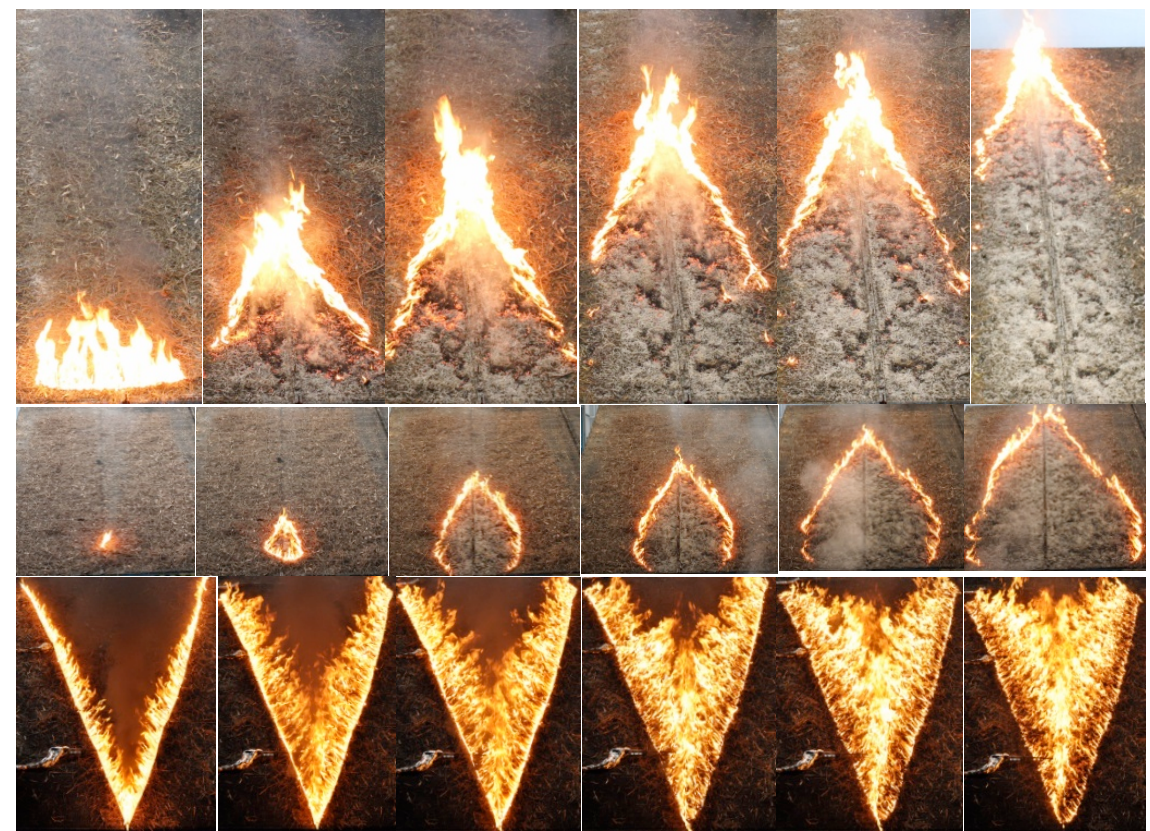

Fig. 3. Photos of fire front shape in experiments for the upslope fire test with line ignition (upper), $\alpha=30^{\circ}$; the upslope fire test with point ignition (middle), $\alpha=30^{\circ}$; jump fire (bottom), $\alpha=20^{\circ}, \theta=30^{\circ}$
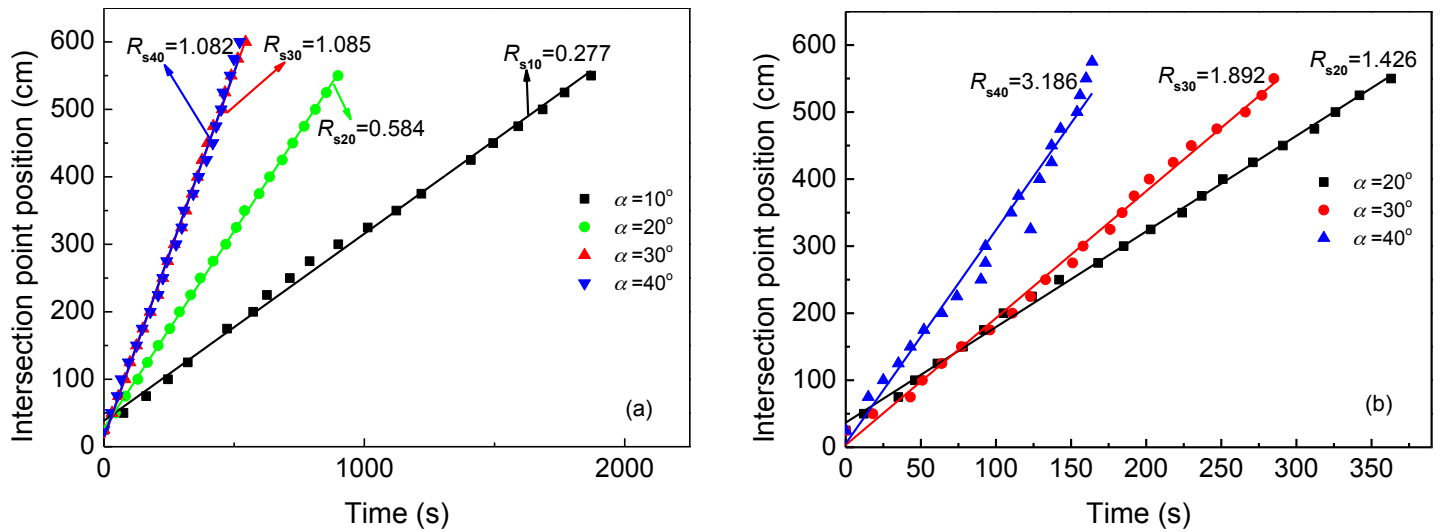

Fig. 4. Intersection point position vs. time in upslope fire tests with line ignition. (a) pine needle; (b) shrub
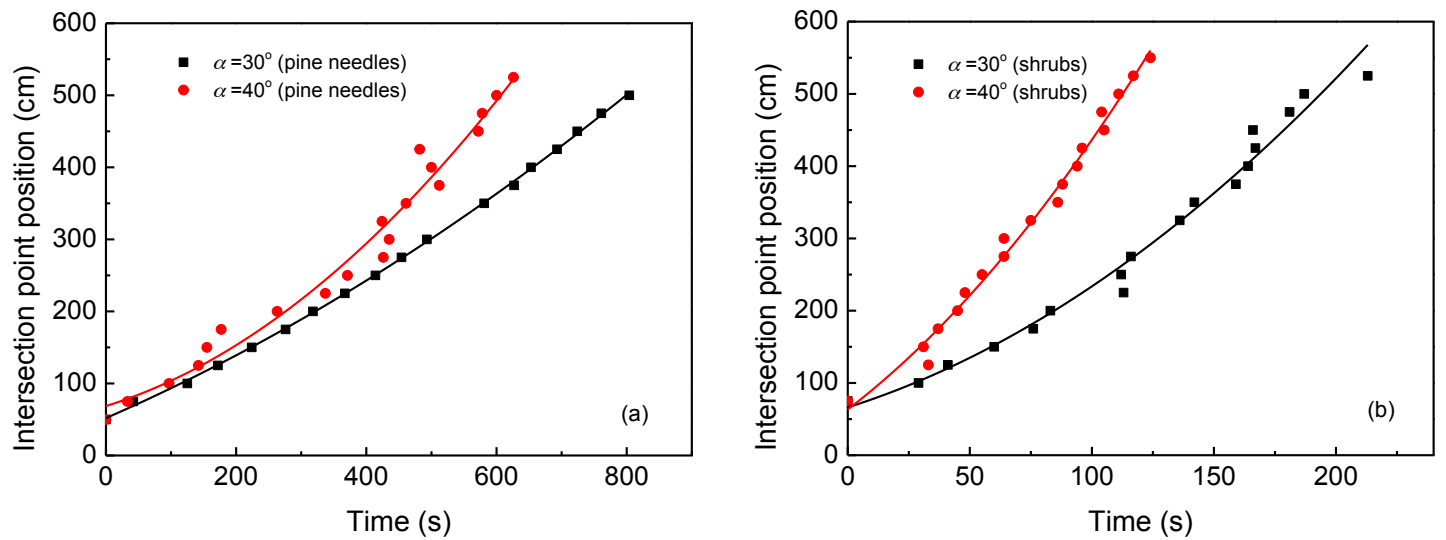

Fig. 5. Intersection point position vs. time in upslope fire tests with point ignition. (a) pine needle; (b) shrub 

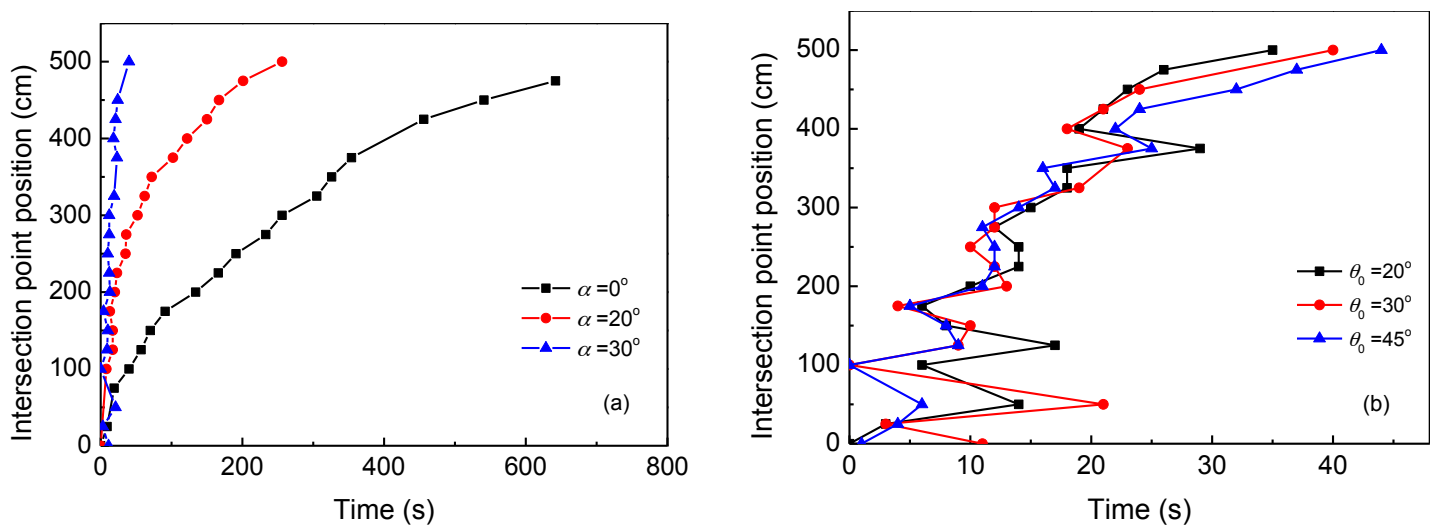

Fig. 6. Intersection point position vs. time in jump fire experiments. (a) $\theta_{0}=30^{\circ}$, with different slope angles; (b) $\alpha=30^{\circ}$, with different initial fire line angles

\section{Non-dimensional ROS}

We define a non-dimensional $\operatorname{ROS} R^{\prime}$ as $R^{\prime}=R / R_{0}$, where $R_{0}$ is the ROS under zero-slope and no-wind condition. This helps remove the effect of environmental conditions (such as ambient temperature and humidity) and fuel moisture content. For determining $R_{0}$, a test of zero slope angle was conducted at the same time of any test of upslope fire or jump fire. Figure 7 presents the data of non-dimensional ROS $R^{\prime}$ versus slope angle $\alpha$ for upslope fires with line ignitions. As seen from the data for pine needle, $R^{\prime}$ begins to increase with increasing slope when $\alpha \geq 20^{\circ}$. The ROS value of shrub is higher than that of pine needle due to that shrub has a higher heat of combustion. The ROS is unsteady for tests with point ignition. As shown in Fig. 8, the data of $R^{\prime}$ versus time for point ignition of pine needle fuel bed can be fitted by polynomial correlations, and after $200 \mathrm{~s}$ from ignition the curves increase with time for both slope angles $\alpha=30^{\circ}$ and $40^{\circ}$. Especially, the values of $R^{\prime}$ for $\alpha=40^{\circ}$ increase much faster than those of $\alpha=30^{\circ}$. Figure $8(\mathrm{~b})$ presents the data for the shrub fuel bed, which shows that $R^{\prime}$ gradually approaches constant values within certain time periods, and then decreases with time.

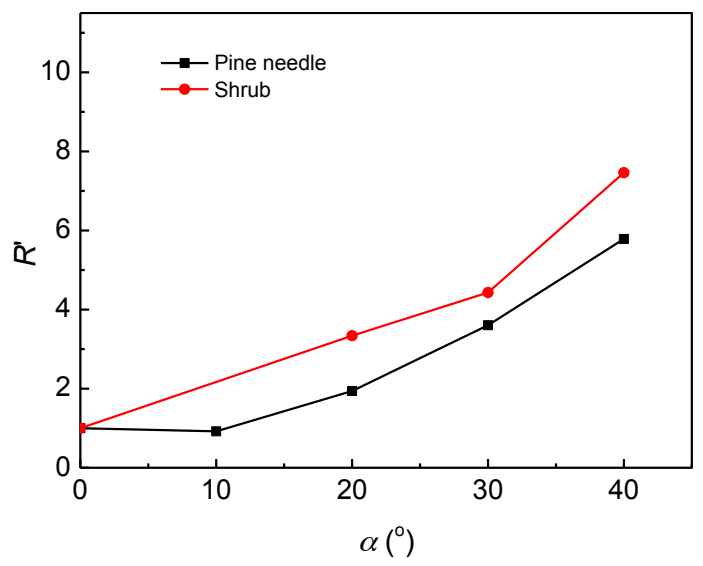

Fig. 7. $R^{\prime}$ versus slope angle for upslope fire tests with line ignitions

For jump fire, in theory after ignition the spread rate of the flame front would first undergo a sharp increase within a short time period, however this process is difficult to be captured in tests. Figure 9 shows the $R^{\prime}$ versus time for two slope angles $\left(\alpha=0^{\circ}\right.$ and $\left.20^{\circ}\right)$, under a specific initial fire line angle $\theta_{0}=30^{\circ}$. As can be seen, the spread rates for the two slope angles both decrease with time, with decays of the decreasing rates. Comparison with Fig. 8(a) shows that the spread rates for upslope fire with point ignition and jump fire have opposite variation modes. 

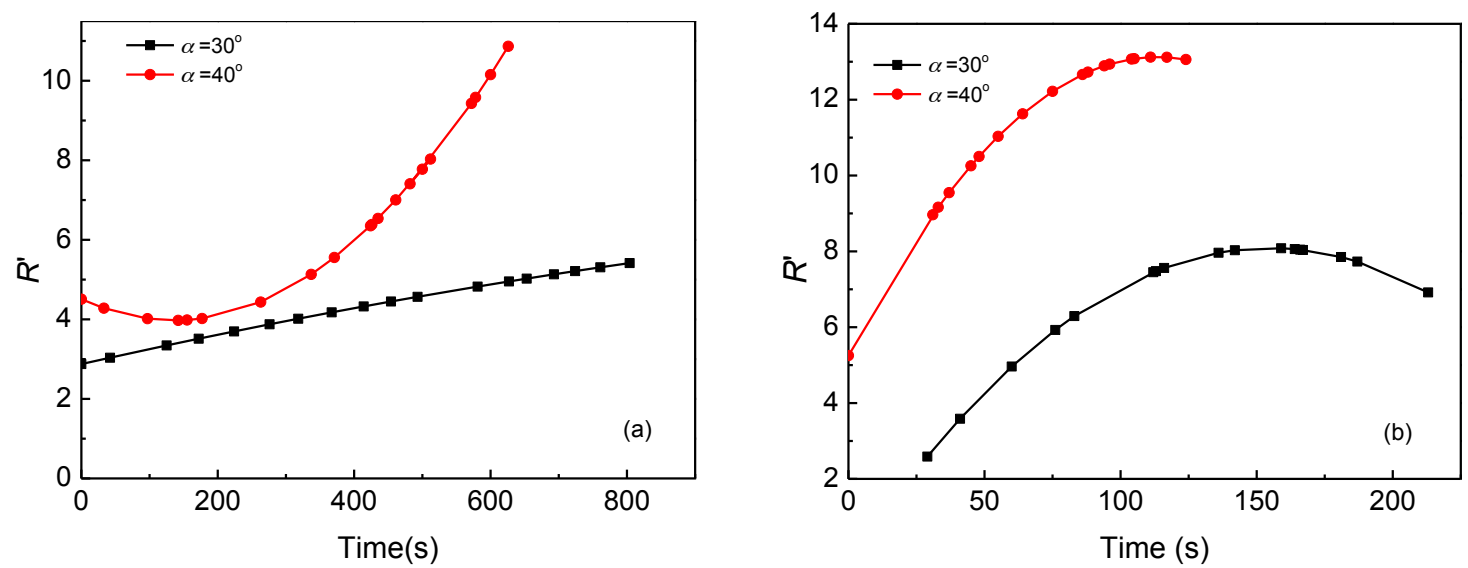

Fig. 8. $R^{\prime}$ versus time for upslope fire tests with point ignition. (a) pine needle; (b) shrub

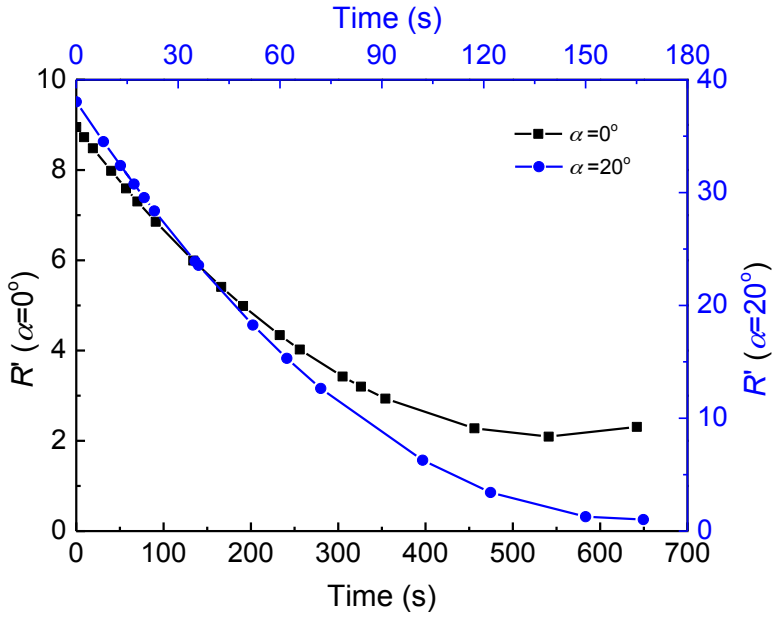

Fig. 9. $R^{\prime}$ versus time for jump fire under a constant initial fire line angle $\left(\theta_{0}=30^{\circ}\right)$

\section{Fire Line Angle}

One similarity between upslope fire and jump fire is that they both involve fire fronts of V-shape. The current experiments showed that the fire line angles varied as a function of time for all the fuels and ignition methods. Figure 10 presents a schematic diagram of the fuel beds of upslope fire and jump fire. Basically, the flame front of an upslope fire spreads outside, while that of a jump fire spreads inside. The inclination angle of a fire line is defined as $\beta=(\pi-\theta) / 2$, which is used for calculating the angular velocity of the fire line.

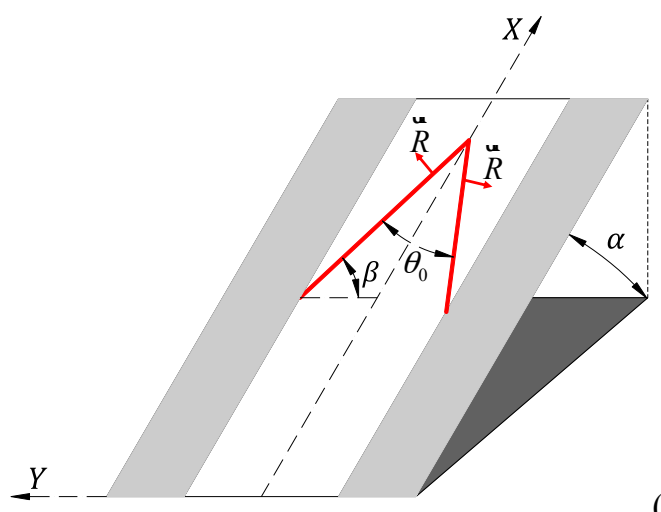

(a)

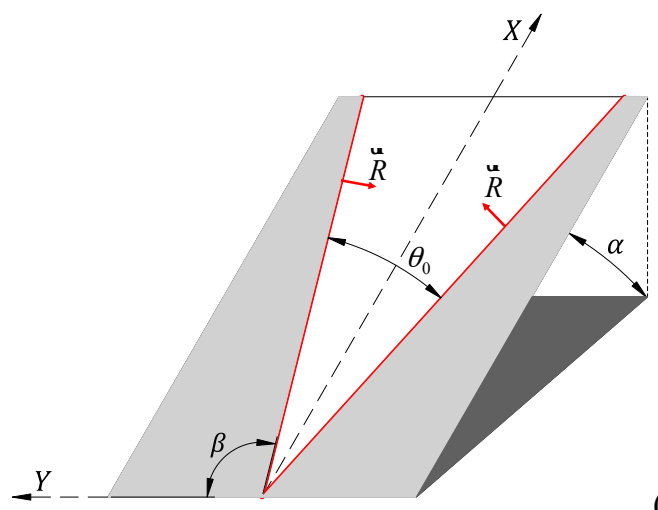

(b)

Fig. 10. Schematic diagram of fuel bed. (a) upslope fire; (b) jump fire 
For upslope fire tests with line ignitions, the lengths of the two fire lines increased with time, thereby the fire line angles decreased. As shown from Fig. 11, for any slope angle, the fire line angle $\theta$, initially being $180^{\circ}$, decreases rapidly with time and finally reaches a constant value, which decreases with slope angle for pine needle due to that larger slope angles involve greater ROS, which causes longer fire lines. Under any specific slope angle, the fire line angle for shrub approaches a stable value which is smaller than that for pine needles, due to the higher burning intensity of shrub fire.
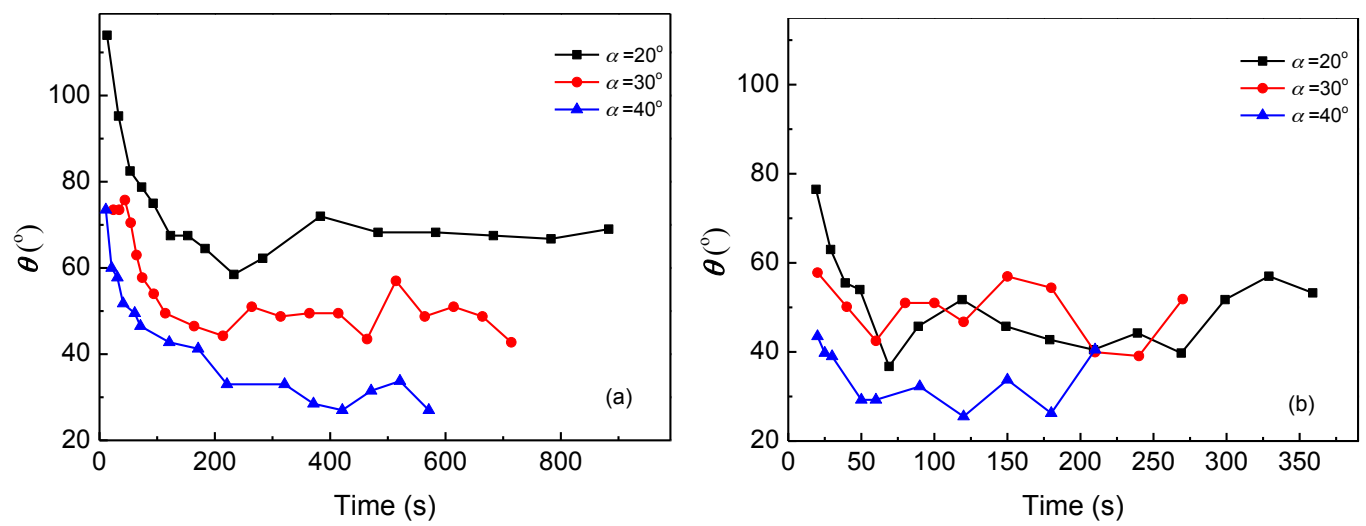

Fig. 11. Fire line angle versus time in upslope fire tests with line ignitions. (a) pine needle; (b) shrub

For slope fire tests with point ignitions, two fire lines were generated after a period from ignition, and then the fire line angle remained nearly constant until the flame reached the end of fuel bed (Fig. 12). In comparison, the fire line angle for shrub involves greater fluctuations than that for pine needles, which implies that the burning of pine needle fire is more stable. Under any specific slope angle, the fire line angle for shrub is smaller than that for pine needles, also due to the higher burning intensity of shrub fire.
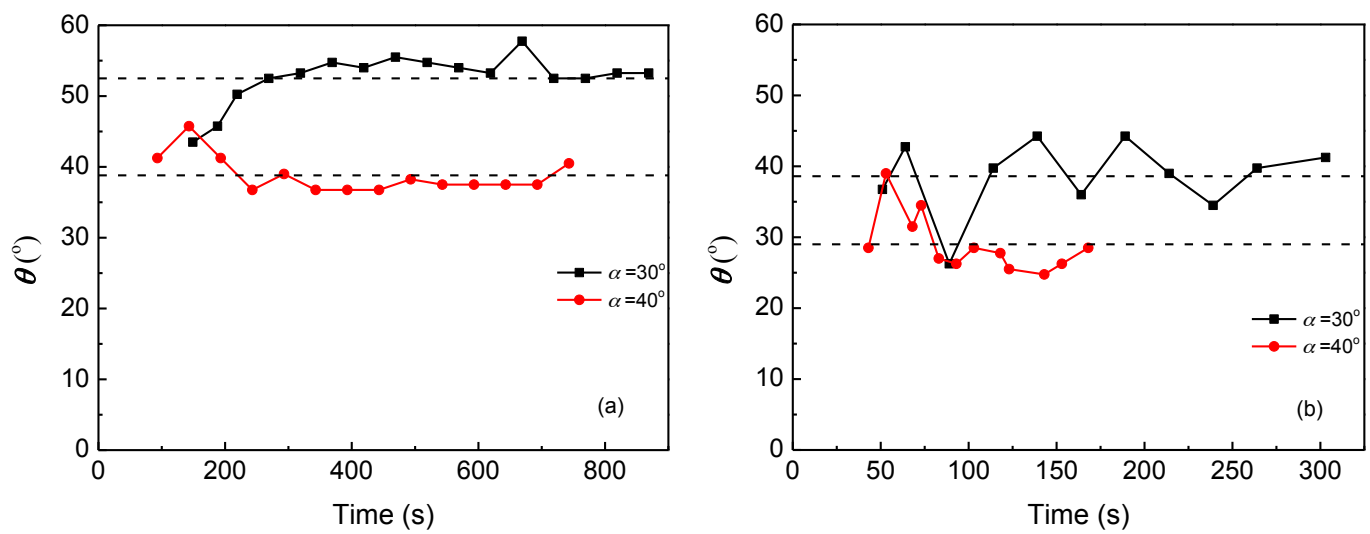

Fig. 12. Fire line angle versus time in upslope fire tests with point ignitions. (a) pine needle; (b) shrub
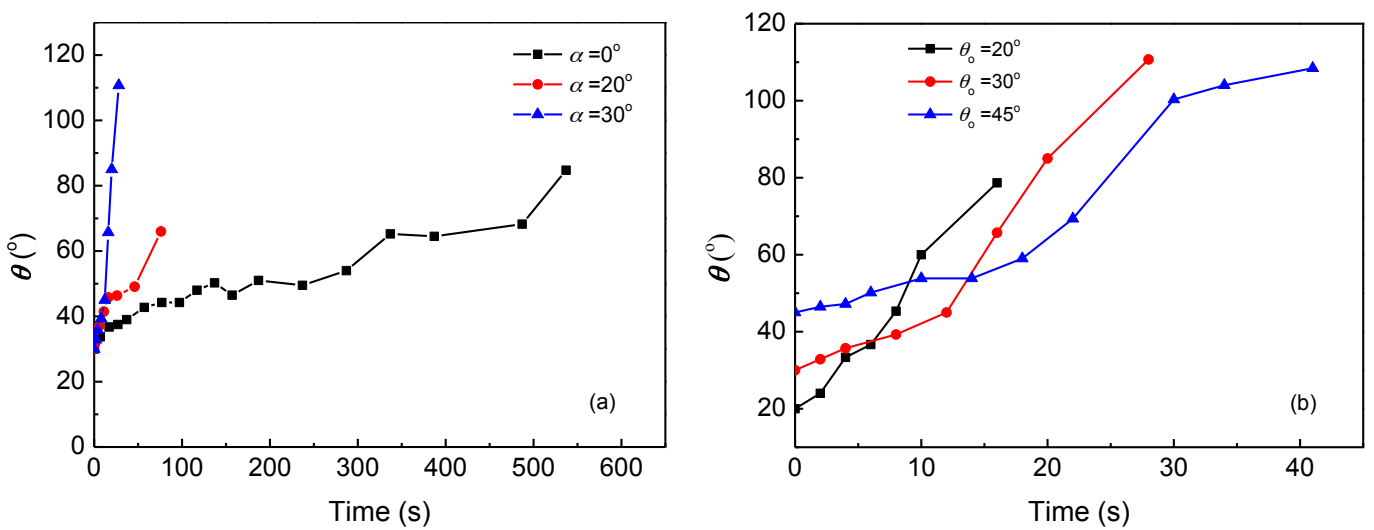

Fig. 13. Fire line angle versus time in jump fire tests with pine needle. (a) $\theta_{0}=30^{\circ}$; (b) $\alpha=30^{\circ}$ 
Figure 13(a) presents the fire line angle of jump fire with time for pine needle, under an initial fire line angle $\theta_{0}=30^{\circ}$. As shown, the fire line angle increases with time for different slope angles, and it involves higher increase rates in higher slope angles. For a specific $\alpha=30^{\circ}$ (Fig. 13(b)), lower initial fire line angles involve higher increase rate with time. By comparisons of Figs. 13-a and 13-b, it can be seen that the fire line angle depends of slope angle more significantly than the initial fire line angle $\theta_{0}$.

\section{Variation of Angular Velocity of Fire Line}

In order to examine the evolution of fire line angle, we define the angular velocity as $w=d \beta / d t$. For upslope tests with line ignition of both kinds of fuels, the angular velocity is initially above zero and then decreases to approach zero value when the fire line angle has been steady (Fig. 14). The results indicate that the angular velocity $w$ has no obvious dependence on the slope angle. For point ignition the angular velocity remains to be around zero in each test. For jump fire, Figure 15 ( $-w$ is used here) shows that the fire line angle increases all the time, and the angular velocity of fire line $w$ remarkably depends on slope angle. Higher slope angles involve great angular velocities.
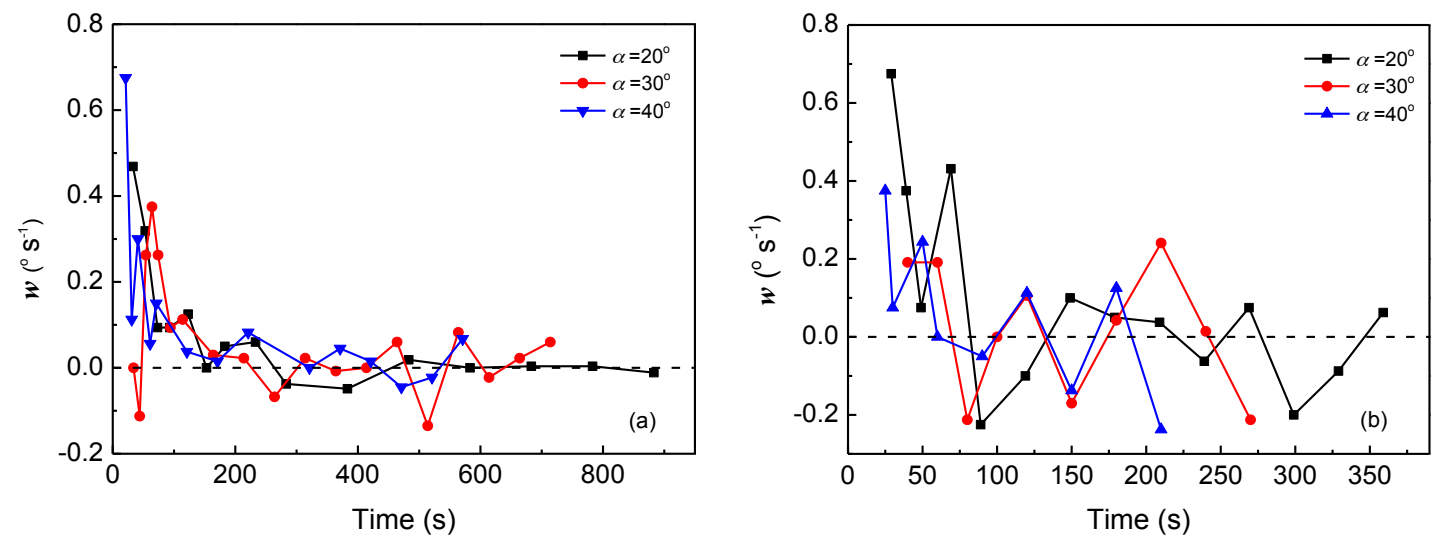

Fig. 14. Angular velocity of fire line versus time for upslope fire tests with line ignitions. (a) pine needle; (b) shrub

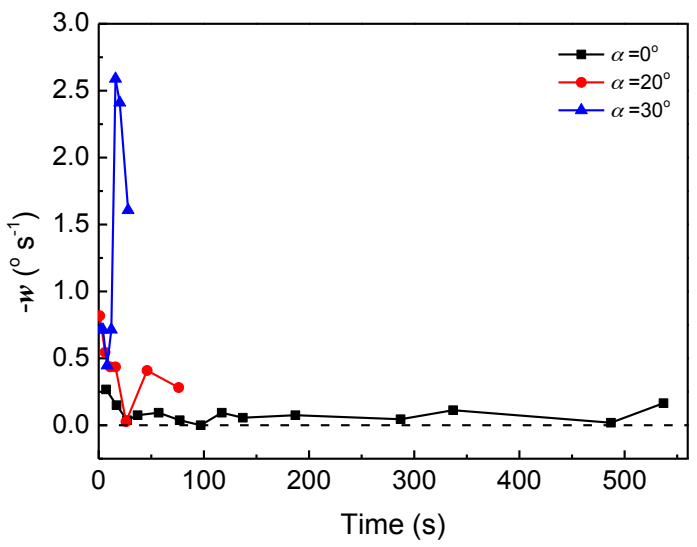

Fig. 15. Angular velocity of fire line versus time for jump fire tests $\left(\theta_{0}=30^{\circ}\right)$

\section{Flame Residence Time}

Flame residence time is the length of time for the fire front to pass a point [1]. One calculation method is by using the visual estimate of the flame front depth divided by its rate of spread, however, it is often difficult to distinguish the flame edge from video images or by stopwatch directly. In this paper the flame residence time is evaluated as the time periods when the measured temperature exceeds $350{ }^{\circ} \mathrm{C}$. Table 1 lists the data of flame residence time under different experimental conditions (some abnormal values due to the broken thermocouples are ignored). It is clear that the flame residence time varies in different positions. The 
overall mean residence time versus slope angle for pine needle is shown in Fig. 16. As seen, for line ignition the values increase under higher slope angle, while for point ignition the values for $30^{\circ}$ and $40^{\circ}$ have no significant differences. For jump fire, under one specific initial fire line angle, the overall mean residence time increases with increasing slope angle. For a specific slope angle of $30^{\circ}$ (see the last three columns in Table 1), the mean residence time remains almost constant with $\theta$.

In the bottom line of Table 1, the average flame front depth for upslope fire tests with line ignition is also listed, which is calculated by the flame residence time multiplied by ROS. Obviously, the flame front depth increases with slope.

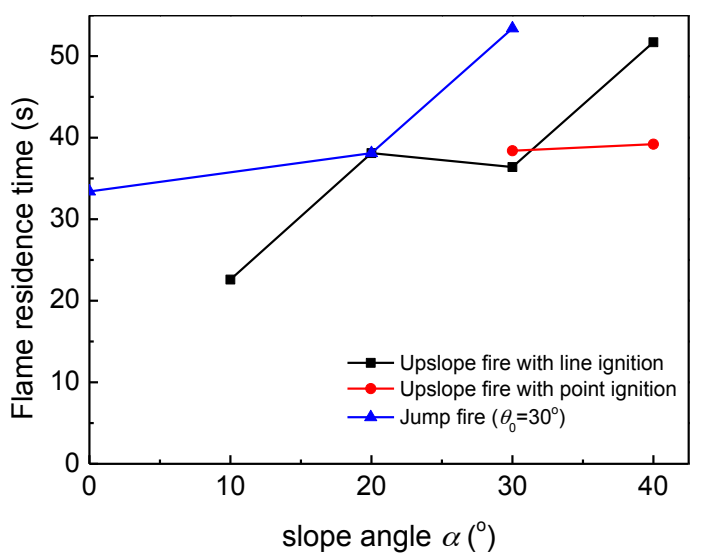

Fig. 16. Residence time as a function of $\alpha$ (pine needle).

Table 1. Data of flame residence time (s) under different experimental conditions (pine needle).

\begin{tabular}{|c|c|c|c|c|c|c|c|c|c|c|c|}
\hline \multirow[b]{2}{*}{$\begin{array}{l}\text { Position } \\
\quad(\mathrm{cm})\end{array}$} & \multicolumn{4}{|c|}{$\begin{array}{c}\text { Line ignition } \\
\text { slope angle } \alpha\left(^{\circ}\right)\end{array}$} & \multicolumn{2}{|c|}{$\begin{array}{c}\text { Point ignition } \\
\text { slope angle } \alpha\left(^{\circ}\right)\end{array}$} & \multicolumn{5}{|c|}{$\begin{array}{l}\text { Jump Fire } \\
\alpha\left(^{\circ}\right), \theta_{0}\left({ }^{\circ}\right)\end{array}$} \\
\hline & 10 & 20 & 30 & 40 & 30 & 40 & $\begin{array}{l}0, \\
30\end{array}$ & $\begin{array}{l}20, \\
30\end{array}$ & $\begin{array}{l}30 \\
30\end{array}$ & $\begin{array}{l}30 \\
20\end{array}$ & $\begin{array}{l}30 \\
45\end{array}$ \\
\hline 0 & & & & & & & 14 & 36 & 23 & 29 & 27 \\
\hline 25 & 43 & 52 & 38 & 72 & & & 52 & 51 & 42 & 28 & 30 \\
\hline 50 & 35 & 42 & 46 & 29 & & 84 & & 24 & 17 & 39 & 48 \\
\hline 75 & 11 & 47 & 46 & 29 & 33 & & 33 & & & & \\
\hline 100 & 14 & 28 & 35 & 38 & 67 & 38 & 30 & & 51 & 62 & 64 \\
\hline 125 & 20 & 26 & 35 & 40 & 59 & 35 & 53 & 55 & 41 & 65 & 61 \\
\hline 150 & & 24 & 32 & 22 & 37 & 51 & 28 & 57 & 61 & 69 & 63 \\
\hline 175 & 23 & 20 & 29 & 33 & 47 & & 23 & 55 & 55 & 65 & 73 \\
\hline 200 & 18 & 30 & 36 & 20 & 19 & & 49 & 55 & 75 & 70 & 68 \\
\hline 225 & 23 & 63 & 53 & 46 & 32 & & 24 & 51 & 77 & 61 & 62 \\
\hline 250 & 30 & 39 & 48 & 29 & 33 & & 34 & 56 & 75 & 71 & 61 \\
\hline 275 & 22 & 43 & 44 & 40 & 28 & 13 & 48 & 46 & 74 & 69 & 57 \\
\hline 300 & 10 & 64 & 40 & 30 & 44 & 35 & 30 & 36 & 66 & 62 & 51 \\
\hline 325 & 15 & 59 & 40 & 88 & & 59 & 42 & 40 & 64 & 61 & 60 \\
\hline 350 & 6 & 30 & 25 & 51 & 33 & 43 & 31 & 36 & & 58 & 50 \\
\hline 375 & 27 & 37 & 25 & 68 & 48 & 16 & 30 & 14 & 63 & 67 & 62 \\
\hline 400 & & 38 & 33 & 49 & 46 & 37 & & 24 & 56 & 73 & 51 \\
\hline 425 & 7 & 30 & 34 & 84 & 34 & & 21 & 18 & 48 & 57 & 47 \\
\hline
\end{tabular}




\begin{tabular}{|c|c|c|c|c|c|c|c|c|c|c|c|}
\hline 450 & 50 & 43 & 42 & 91 & 29 & 28 & 28 & 27 & 46 & 57 & 44 \\
\hline 475 & 36 & 35 & 35 & 61 & 26 & 54 & 32 & 28 & & 57 & 46 \\
\hline 500 & 23 & 47 & 36 & 75 & & 43 & & 15 & 27 & 46 & 38 \\
\hline 525 & 23 & 27 & 35 & 57 & & 13 & & & & & \\
\hline 550 & 18 & 16 & 38 & 74 & & & & & & & \\
\hline Average (s) & 23 & 38 & 36 & 52 & 38 & 39 & 33 & 38 & 53 & 58 & 53 \\
\hline ROS (cm/s) & 0.28 & 0.58 & 1.09 & 1.08 & & & & & & & \\
\hline $\begin{array}{c}\text { Flame front } \\
\text { depth (cm) }\end{array}$ & 6.26 & 22.24 & 39.45 & 55.89 & & & & & & & \\
\hline
\end{tabular}

\section{Radiant Heat Transfer}

In this paper, it is assumed that the flame is an isothermal sheet with a uniform emissivity [16]. Thus the heat radiation from the flame (denoted by $A_{1}$ ) to any finite area of $A_{2}$ on the surface of the fuel bed is

$$
Q=A_{1} F_{12} \varepsilon \sigma T^{4}
$$

The ambient temperature $T_{w}$ is very small compared to the flame temperature $T$, and thus the heat flux is

$$
q=\frac{A_{1}}{A_{2}} F_{12} \varepsilon \sigma T^{4}
$$

The view factor from flame to fuel surface is

$$
F_{12}=F_{A_{1} \rightarrow A_{2}}=\frac{1}{A_{1}} \iint_{A_{1}} \frac{\cos \theta_{1} \cos \theta_{2}}{\pi R^{2}} d A_{2} d A_{1}
$$

Here $\theta_{1}, \theta_{2}$ are the polar angles. The non-dimensional heat transfer is employed to simplify the discussion on flame emissivity and temperature. It is expressed as

$$
q^{*}=\frac{q}{\varepsilon_{\text {flame }} \sigma T_{f}^{4}}=\frac{1}{A_{2}} \iint_{A_{1}} \int_{A_{2}} \frac{\cos \theta_{1} \cos \theta_{2}}{\pi R^{2}} d A_{2} d A_{1}
$$

When fuel area $A_{2}$ is infinitesimal,

$$
q^{*}=\int_{A_{1}} \frac{\cos \theta_{1} \cos \theta_{2}}{\pi R^{2}} d A_{1}
$$

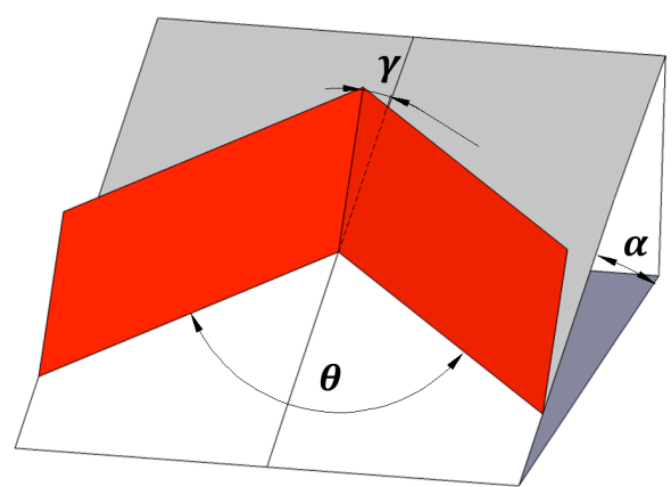

(a)

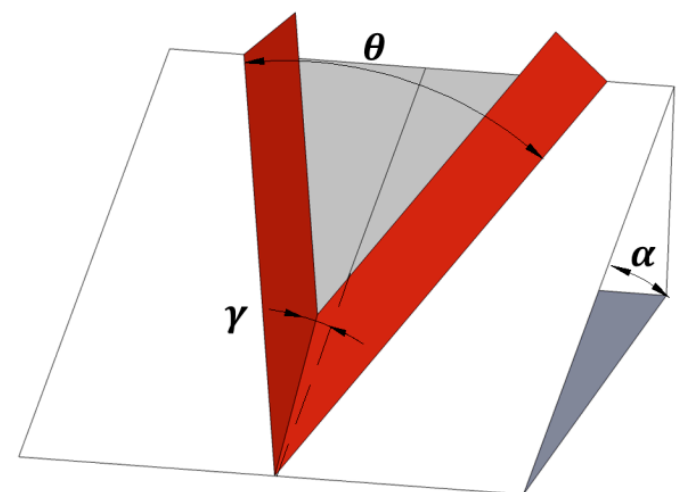

(b)

Fig. 17. Sketch map of heat radiation model. (a) upslope fire; (b) jump fire

Figure 17 depicts a model for upslope fire (line ignition) and jump fire, where the heat radiation from flame surface to fuel bed is symmetrical to the centerline of the fuel bed. The heat radiation flux depends on slope 
angle $\alpha$, fire line angle $\theta$, flame tilting angle $\gamma$, flame length and position of fuel element. For examining the effect of fire line angle $\theta$ on flame radiation to the centerline of the fuel bed, we use a new nondimensional heat flux as in Eq. 6, while other parameters are fixed, e.g. $\gamma=30^{\circ}, L=0.5 \mathrm{~m}$.

$$
q^{*}=f(\theta)
$$
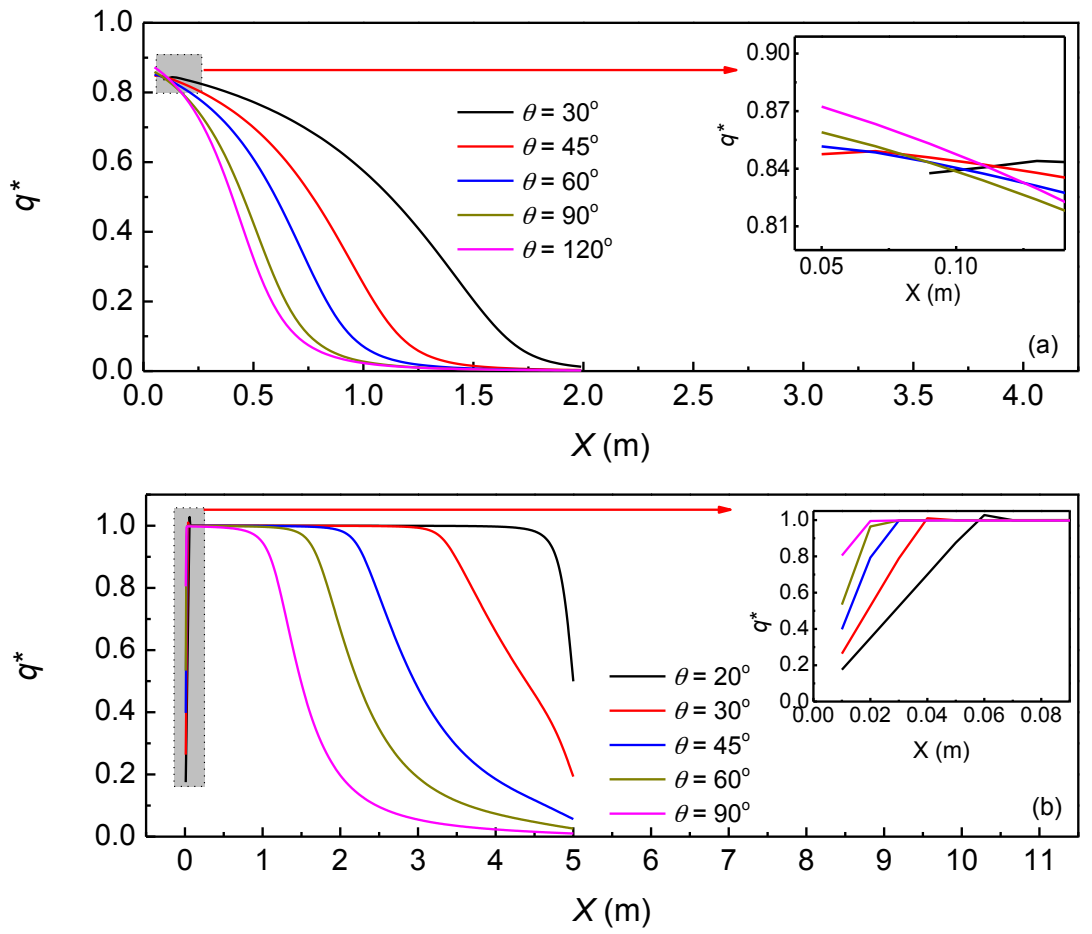

Fig. 18. Non-dimensional heat radiation flux in centerline. (a) upslope fire; (b) jump fire

The calculation of the flame radiation for upslope fire and jump fire are similar due to their symmetric geometric configurations. For radiation to centerline of the fuel bed, we only need to calculate the flame radiation from any fire line on one side and then double the values. For a fuel element which is not on the centerline, the radiations from the fire lines of both sides should be calculated.

In this work algorithms of double line integration (2LI) and double area integration (2AI) are employed to compute $q^{*}$, and the results are shown in Fig. 18, in which $X$ is the distance away from the intersection point of the two fire lines along the fuel bed centerline. A gird size of $100 \times 100$ is used for the flame sheet surface, and that of $10 \times 10$ is used for the infinitesimal area element of fuel bed along the centerline of the fuel bed.

Heat radiation is mainly used for preheating unburnt fuel ahead of the fire front. For upslope fire tests with line ignition, from Fig. 18(a) it is clear that the non-dimensional heat radiation decreases along the centerline. When the fire line angle decreases from $120^{\circ}$ to $30^{\circ}$, the decrease rate of non-dimensional heat radiation versus $X$ decays. This implies that small fire line angle fire has a longer preheating range, which could lead to higher ROS. From the imbedded plot in Fig. 18(a) it can be seen that for fuel elements very close to the intersection point of the two fire lines, $q^{*}$ increases with increasing fire line angle.

As shown in Fig. 18(b), the non-dimensional heat radiation $q^{*}$ for jump fire develops in three ranges: (1) It increases sharply within an initial short distance; (2) It keeps almost constant in the second range, and smaller fire line angles involve longer distance of this range; (3) It decreases quickly until the end of the fuel bed. It is important to note that the sharp increase of $q^{*}$ in the initial short distance may be considered to be concerned with the sudden change of ROS in the initial stage of a jump fire. 


\section{CONCLUSIONS}

This paper presents an elementary experimental research to investigate the difference and similarity between upslope fire and jump fire, by examining the rate of spread, fire line angle, angular velocity of the fire line, flame residence time and non-dimensional radiant heat transfer.

For upslope fires with line ignition, the fire front spreads upslope in a quasi-steady way in global sense, while for point ignition the ROS increases with time. In comparison, the ROS in jump fire increases to a very high value in a very short period and then gradually decreases. For the intersection point position which varies with time, the jump fire and the upslope fire with point ignition have opposite evolution modes. The non-dimensional ROS for upslope fire increases with slope angle. For jump fire, the ROS depends on slope angle more significantly than initial fire line angle.

For upslope fires with line ignition, the fire line angle will decrease from the initial $180^{\circ}$ to a steady small value. For point ignition, once fire lines are generated, the fire line angle remains steady. For jump fire, the fire line angle increases with time.

The angular velocity of fire lines does not depend on slope angle in an upslope fire with line ignition, while for jump fire, the angular velocity varies with slope angle.

For upslope fires with line ignition, the flame residence time increases with slope angle, while it remains almost constant for upslope tests with point ignition. For jump fire, under one specific initial fire line angle, the overall mean residence time increases with increasing slope angle.

Non-dimensional heat radiation for fuel preheating could effectively explain the ROS evolution in upslope fire with line ignition and jump fire. Especially the non-dimensional heat radiation has a sharp increase in the initial short distance, which can be an evidence to explain the sudden change of ROS in the initial stage of a jump fire.

\section{ACKNOWLEDGEMENTS}

This work was sponsored by the National Basic Research Program of China (973 Program, No. 2012CB719702), the National Key Technology R\&D Program under Grant 2011BAK07B01-02, and National Natural Science Foundation of China under Grant 51120165001 and 51076148. This work was also financially supported by Jiangsu Science-technology Support Plan Projects (No.BE2012671). Naian Liu was supported by the Fundamental Research Funds for the Central Universities (No. WK2320000020). The authors thank their colleagues who supported the experimental work in the Fire Research Laboratory, namely Ricardo Oliveira and Nuno Luis.

Correspondence to this paper should be addressed to Prof. Naian LIU, liunai@,ustc.edu.cn.

\section{REFERENCES}

[1]. Wotton, B.M., Gould, J.S., McCaw, W.L., Cheney, N.P., and Taylor, S.W., (2012) Flame temperature and residence time of fires in dry eucalypt forest, International Journal of Wildland Fire, 21(3): 270, http://dx.doi.org/10.1071/WF10127.

[2]. Viegas, D.X., (1994) Some Thoughts on the Wind and Slope Effects on Fire Propagation, International Journal of Wildland Fire, 4(2): 63-64, http://dx.doi.org/10.1071/WF9940063.

[3]. Dupuy, J.L., (1995) Slope and Fuel Load Effects on Fire Behavior - Laboratory Experiments in Pine Needles Fuel Beds, International Journal of Wildland Fire, 5(3): 153-164, http://dx.doi.org/10.1071/WF9950153.

[4]. Santoni, P.A., Balbi, J.H., and Dupuy, J.L., (2000) Dynamic modelling of upslope fire growth, International Journal of Wildland Fire, 9(4): 285-292, http://dx.doi.org/10.1071/WF00004.

[5]. Viegas, D.X., (2004) On the existence of a steady state regime for slope and wind driven fires, International Journal of Wildland Fire, 13(1): 101-117, http://dx.doi.org/10.1071/WF03008. 
[6]. Morandini, F., Simeoni, A., Santoni, P.A., and Balbi, J.H., (2005) A model for the spread of fire across a fuel bed incorporating the effects of wind and slope, Combustion Science and Technology, 177(7): 1381-1418, http://dx.doi.org/10.1080/00102200590950520.

[7]. Viegas, D.X., (2007) Zigzag shape of the fire front, International Journal of Wildland Fire, 16(6): 763-764, http://dx.doi.org/10.1071/WF06135.

[8]. Rothermel, R.C., "A mathematical model for predicting fire spread in wildland fuels," F.S. USDA, Intermountain Forest and Range Experiment Station., 1972, 40p.

[9]. Sharples, J., (2008) Review of formal methodologies for wind-slope correction of wildfire rate of spread, International Journal of Wildland Fire, 17(2): 179, http://dx.doi.org/10.1071/WF06156.

[10]. Dupuy, J.L., Marechal, J., Portier, D., and Valette, J.C., (2011) The effects of slope and fuel bed width on laboratory fire behaviour, International Journal of Wildland Fire, 20(2): 272-288, http://dx.doi.org/10.1071/WF09075.

[11]. Silvani, X., Morandini, F., and Dupuy, J.L., (2012) Effects of slope on fire spread observed through video images and multiple-point thermal measurements, Experimental Thermal and Fluid Science, 41(99-111, http://dx.doi.org/10.1016/j.expthermflusci.2012.03.021.

[12]. Viegas, D.X., Raposo, J.R., Davim, D.A., and Rossa, C.G., (2012) Study of the jump fire produced by the interaction of two oblique fire fronts. Part 1. Analytical model and validation with no-slope laboratory experiments, International Journal of Wildland Fire, 21(7): 843-856, http://dx.doi.org/10.1071/WF10155.

[13] Viegas, D.X., (2005) A mathematical model for forest fires blowup, Combustion Science and Technology, 177(1): 27-51, http://dx.doi.org/10.1080/00102200590883624.

[14] Viegas, D.X., (2006) Parametric study of an eruptive fire behaviour model, International Journal of Wildland Fire, 15(2): 169, http://dx.doi.org/10.1071/WF05050.

[15] Viegas, D.X. and Simeoni, A., (2011) Eruptive Behaviour of Forest Fires, Fire Technology, 47(2): 303-320, http://dx.doi.org/10.1007/s10694-010-0193-6.

[16] Koo, E., Pagni, P., Stephens, S., Huff, J., Woycheese, J. and Weise, D.R., (2005) A Simple Physical Model For Forest Fire Spread Rate. Fire Safety Science 8: 851-862. http://dx.doi.org/10.3801/IAFSS.FSS.8-851. 